\title{
O TEMPO NO TERCEIRO MUNDO DE GLAUBER : ROCHA: O ROTEIRO CINEMATOGRÁFICO COMO GÊNERO LITERÁRIO
}

\section{TIME IN GLAUBER ROCHA'S TERCEYRO MUNDO: THE CINEMATOGRAPHIC SCREENPLAY AS A LITERARY GENRE}

Rafaela Rogério Cruz (UFRPE) ${ }^{1}$

\section{RESUMO}

Glauber Rocha, numa carta a Augusto Carlos Calil expressou vontade de reunir em antologia uma série de roteiros seus. $\mathrm{O}$ diretor baiano e toda a sua obra cinematográfica já gozam do respeito tanto da crítica quanto do público, tendo reconhecida a sua importância na produção artístico/cultura brasileira do século XX, contudo seus roteiros, base literária dos filmes, estão ainda para ser descobertos como obra literária independente. Este artigo, através da análise da categoria tempo, tem como objetivo entender como o roteiro articula conceitos de ficção e narratividade em comparação com o romance e o drama, gêneros literários já bem estabelecidos. Com o intuito de cavar para o roteiro um lugar nos estudos literários, nossa leitura é guiada por teóricos cuja preocupação com a narrativa literária é um grande legado para a teoria e crítica, sendo alguns deles: Roland Barthes (1972), Gerárd Genette (1979) e Tzvetan Todorov (2006).

PALAVRAS-CHAVE: roteiro cinematográfico; gêneros literários; Glauber Rocha; tempo na narrativa.

1 Mestra e doutoranda em Teoria da Literatura pela Universidade Federal de Pernambuco (UFPE) e professora de Literaturas de língua inglesa na Universidade Federal Rural de Pernambuco - Unidade Acadêmica de Serra Talhada (UFRPE/UAST).

Email: rafaelarcruz@gmail.com 


\section{ABSTRACT}

In a letter to his friend Algusto Carlos Calil, Glauber Rocha expressed his will to gather in a single anthology some of his screenplays. The director - born in the northeast state of Bahia - and all his cinematic production have enjoyed the respect and admiration not only of the specialized critics, but also from the general audience and his importance to the artistic and cultural production in $20^{\text {th }}$ century Brazil. However, his screenplays, the literary basis of his films, are still to be discovered as independent literary work. Through the analysis of the category time, this paper aims to understand how the screenplay articulates concepts of fiction and narrativity when compared to the novel and the drama, well established literary genres. Insofar that the intention is to carve for the screenplay a place in literary studies, our research is guided by authors whose work on the literary narrative was pivotal for both theory and criticism: Roland Barthes (1972), Gerárd Genette (1979) and Tzvetan Todorov (2006).

KEYWORDS: screenplay, literary genres, Glauber Rocha, time in the narrative.

\section{INTRODUÇÃO}

O livro Roteiros do Terceyro Mundo, organizado por Orlando Senna, reúne, numa primeira parte, cinco roteiros escritos por Glauber Rocha e, numa parte posterior, a transcrição textual, feita por Orlando Senna, dos oito longas de ficção de Glauber numa edição que, apesar de haver sido idealizada pelo próprio diretor, só foi publicada postumamente. Numa das cartas que escreve a Calil com instruções sobre a edição, Glauber expressa o seu desejo de preservar a base literária de seus filmes.

Gostaria de publicar estes roteiros num só volume - de umas 300 páginas- sob o título de "Roteiros do Terceyro Mundo" porque estes 8 filmes são referentes ao III Mundo e marcam uma fase do meu trabalho. Se isto for possíveldepois acertaremos por carta ou telefone detalhes da edição. A edição seria bom para preservar a base literária dos filmes 
- pois estes roteiros podem ser refilmados + televizados + montados em teatros e ainda funcionam como romances ou novelas etc... (ROCHA, 1985)

Apesar do papel de destaque que o diretor baiano ocupa na tradição do cinema nacional, essa sua empreitada literária amarga um grave esquecimento. A obra, publicada em 1985 e nunca mais reeditada, é artefato raro, indisponível em livrarias, flutua pelas prateleiras dos sebos brasileiros. Não apenas são os Roteiros do Terceyro Mundo prova da grandeza estética de Glauber, como também documento seminal do Cinema Novo, provavelmente o mais importante movimento de vanguarda na história do cinema brasileiro. Tamanho descaso com uma obra tão importante é explicado, entre outros fatores, pelas lentes da indiferença e do desdém com as quais a cultura literária mundial enxerga o roteiro cinematográfico enquanto gênero textual.

Este trabalho, que parte primeiramente como inquietação resultante da experiência estética, não apenas com a obra de Glauber Rocha, mas com outros roteiros. Desta forma, é mister destacar que há sim empenho intencional por trás do exercício comparativo que será realizado: situar os textos do Terceyro Mundo em uma relação tencionada com outras formas do discurso literário previamente admitido pela tradição.

Muito embora seja necessário uma discussão aprofundada sobre a exclusão do roteiro do cânone literário, discussão que precisa passar, ao menos, pelo campo da história das formas e da sociologia da arte, o espaço de um artigo não nos permite tal empreitada. Por isso, o exercício analítico que se seguirá terá como esforço metodológico a articulação de regras previamente notadas nos gêneros romance e drama.

Dado que o cinema - onde dizem estar a utilidade do roteiro é indiscutivelmente a grande forma narrativa da modernidade, nascido literalmente de suas engrenagens e máquinas em resposta aos anseios e mudanças paradigmáticas de tal episteme, busquei aproximar-me do roteiro através do seu caráter narrativo, o que explica a abordagem influenciada pela teoria e crítica estruturalista que tinha na estrutura narrativa um de seus principais objetos de estudo.

A escolha do texto de Glauber como corpus de análise serve a dois propósitos, o primeiro de resgatar uma obra particular cuja importância 
não é reconhecida justamente por sua difícil acessibilidade, o segundo para exemplificar alguns pontos cruciais do funcionamento da forma roteiro : que transcendem a particularidade do texto de Rocha. Essa empreitada segunda visa, claramente, obter resultados através de uma experiência observadora, mas - faz-se crucial destacar- não prescritiva.

Escreve-se ou sobre a literatura em geral ou sobre uma obra; e existe uma convenção tácita segundo a qual enquadrar várias obras num gênero é desvalorizá-las. Essa atitude tem uma boa explicação histórica: a reflexão literária da época clássica, que tratava mais dos gêneros do que das obras, manifestava também uma lamentável tendência: a obra era considerada má se não obedecia suficientemente as regras do gênero. (TODOROV, 2006, p.93)

A visão dos Roteiros do Terceyro Mundo é essa da grande obra que ao transcender o exercício corrente da forma roteiro, estabelece essa mesma forma através de sua negação.

Mais uma vez, o espaço - ou seria o tempo? - do gênero artigo restringirá a proporção do trabalho. A análise se preocupará então apenas com uma das categorias da narrativa: o tempo; e como ela está articulada em um dos textos que compõe o livro: Terra em transe.

\section{Sobre o tempo no Terceyro Mundo}

Syd Field, embora sua experiência com o estudo da teoria literária não seja de modo algum extenso, problematizou a diferença entre o roteiro e o drama de maneira simples: a ação do drama ocorre através da linguagem, a do roteiro através da imagem. Por mais demasiadamente redutiva tal assertiva possa parecer, ela lança uma potente luz que nos ajuda a compreender onde o roteiro e, como é o nosso caso, os textos de Glauber se localizam entre o que se acostumou chamar texto narrativo e texto dramático.

No texto de Terra em Transe podemos ver claramente o papel desempenhado pelo, já clássico, mandamento: mostrar antes de dizer como medida para avaliar a competência do escritor. Para que possamos melhor entender, observemos mais uma vez o trecho: 
Sucessão de TRAVS - sequencia desordenada, vibrante, cruel - sobre ela os letreiros, não todos. Ruídos naturais, de gritos e tiros.

Um negro corre no lixo, armado. Cachorros o perseguem. Policiais armados. Tiroteio. Mais de vinte contra um. Herói do lixo, sobre os detritos, camisa aberta ao peito, gritando como um selvagem africano, o Negro dispara suas últimas balas e é ferido. Cai morto. Ganem os cães. Tiram fotografias do Negro: sua cara sobre o lixo.

Em montagem brutal - outros planos de violência movimento ativo dilacerante - jazzístico - afro-sambaÁfrica-Ásia.

Primeiramente é necessário que se diga que a transcrição tenta seguir o máximo a formatação presente no livro. Desta forma logo estamos confrontados com, antes mesmo que leiamos o texto, a formatação quase paragráfica com que se está acostumado na prosa literária, mas o uso particular da pontuação nos alerta para uma crucial especificidade. Enquanto pode-se dizer que o texto literário em prosa mais corrente, no caso o romance, articula o seu ritmo como no sentido de gerar seu próprio mundo, ou seja, o mundo que vive sobre suas próprias regras. No trecho acima podemos perceber a necessidade de se acercar de um ritmo da percepção do mundo real, claramente nunca se acercará de verdade, pois a tentativa de descrever a cena no ritmo que o olho a perceberia caso fosse real é, apenas, uma potente ilusão. As vírgulas são quase como as pausas do olho que pisca, fechando-se para rapidamente tornar a abrir e reconhecer (ou aperceber-se) de outro aspecto ao seu redor. Essa ilusão do olho que lê transformado em olho que vê é a grande ferramenta do texto cinematográfico.

Em seu texto $O$ efeito de real (1972), Roland Barthes nos traz uma interessante consideração sobre a descrição e a existência do detalhe aparentemente inútil na prosa realista. $\mathrm{O}$ escritor defenderá que nenhum pormenor do texto pode ser tomado como sem significado e, consequentemente, descartável. Para responder algumas opiniões que acreditam ser os detalhes apenas referenciais diretos de suas existências no mundo empírico e, assim sendo, despidos de um significado outro 
dentro da estrutura do tecido narrativo, Barthes oferece a ideia da ilusão do referencial.

A verdade desta ilusão é a seguinte: suprimido da denotação, o <<real〉> volta para ela, a título de significado de conotação; pois no mesmo instante que esses detalhes são supostos denotarem diretamente o real, eles não fazem mais que os significarem, sem dizê-lo: (...) não dizem nada mais que isso: somos o real; é a categoria do <<real > (e não seus conteúdos contingentes) que é então significada. (BARTHES, 1972)

Um caminho de raciocínio lógico a ser percorrido logo levantará que o roteiro, como manual instrutivo, quer denotar exatamente seu detalhe, sua presença objeto no filme: uma indicação de cenário a ser tomada em exatidão, mas para pensar melhor tal questão, tomemos outro trecho de Terra em Transe, a sequência de número quatro:

Uma casa moderna, entre árvores, colocada para o alto. O carro de Paulo. Paulo sobre as escadas da casa, está de terno escuro.

Interior. Casa de Silvino sentado, camisa aberta. Aparece ao fundo, por uma porta de vidro, Paulo: fotos da conquista espacial, fotos de Silvino.

Silvino lê jornais. Silvino nota a presença depois de ouvir um leve ruído. Reergue-se do seu sono. A imagem de Paulo que se aproxima. Silvino compõe-se, sente Paulo, levanta-se e o abraça com grande emoção. Música clássica.

Se aceitássemos o texto acima como puramente um texto técnico, certamente que em funcionalidade não diferiria muito de um manual para montar uma instante ou aparelho eletrônico. Façamos o exercício de pensar que os conjuntos de palavras: casa moderna; carro de Paulo e terno escuro denotam peças da montagem de um aparelho, no caso do texto acima o aparelho é uma sequência. No texto de um manual de montagem de aparelho, quando lemos a instrução do fabricante: "pegue a rosca de número 5" não podemos, certamente, esperar que uma rosca número 6 funcione. Ora, alguém pode dizer, mas se poderia pegar qualquer rosca 
: número 5, o que é verdade. Contudo, existe uma quantidade $\mathrm{x}$ - por : maior que seja - de roscas número 5 do mundo, uma quantidade real e verificável. Tal quantidade pode ser conhecida e existe no mundo. Desta forma, o texto dos manuais de aparelho lida diretamente com a realidade que lhe é externa o quanto se é possível, sua previsão - i.e o aparelho a ser montado - é realizável no real empírico que compartilhamos. No caso do roteiro não funciona assim. O carro de Paulo não existe no mundo. Existe sim uma quantidade determinada de Paulos do mundo e outra de carros, mas $O$ carro de Paulo não está sendo fabricado e vendido junto com manuais para construir um filme. O que poderá vir disso é uma imitação que o filme venha a fazer, numa distinção quase platônica, onde $O$ carro de Paulo existe como essa forma essencial apenas no texto de Glauber e o filme virá para imitá-la. Virá tentar tocar o que não pode ser tocado.

Tanto não pode tocá-la que nem sequer houve o intento, a sequência acima não tem sua tradução no filme que conhecemos por Terra em transe. É claro perceber que Terra em transe (o texto) e Terra em transe (o filme) não poderão nunca ser as mesmas coisas, nem sequer a previsão ou realização do outro. Assim, a camisa aberta, a porta de vidro, a música clássica não são as indicações para o cenógrafo ou para o que cuidará da trilha sonora do filme, antes eles falam de Paulo e de Silvino, de quem são como pessoas-personagens, da relação de um com o outro, da atmosfera e tempo do encontro i.e de nada que não seja o próprio texto. $A$ ilusão referencial da qual fala Barthes está no texto de Glauber, e no roteiro em geral, ainda mais verticalizada, ainda mais ilusória. Pois ela faz acreditar que cada pormenor de coisas será realizável, que à exatidão sairá do papel não para a cena do filme - pois a cena também ficção, ilusão-, mas para o set de filmagens, este sim, tão real quanto possível. A ilusão referencial no roteiro pretende-se como o índice backwards. Que instrução realizável pode haver ao final do discurso de Silvino quando o texto diz: "Silvino movimenta-se, crescendo para Paulo. Paulo é transido pelo delírio de Silvino"? Ora, não caberá ao leitor - aquele que deseja simplesmente ler o texto e aquele que deseja fazer um filme - tentar buscar, antes de tudo, desvendar o significado da ideia de "Silvino crescendo para Paulo", ou, ainda mais fortemente, "Paulo transido pelo delírio de Silvino"? O delírio pelo qual Paulo será transido existe apenas - como se pouco fosse 
- na linguagem, na fala de Silvino, no texto, no aprofundamento de sua diegese: o delírio está num tempo interno dentro da ficção principal, está num nível outro, no nível literário. Uma vez que acaba seu discurso (seu delírio), o texto diz "Silvino e Paulo. As luzes estão acesas", não é uma indicação de ambientação, antes é o aviso de que estamos de volta no tempo diegético principal.

O exercício feito até agora, no sentido de expor em alguns poucos exemplos o posicionamento que aqui se pretende defender: o roteiro como gênero que ultrapassa largamente o ideal instrutivo e técnico e o texto de Glauber como uma rica fonte para a defesa de tal tese, já serviu para destacar dois pontos muito importantes a serem observados para o entendimento do guião cinematográfico como narrativa ficcional literária: o tempo e a personagem. Entendendo-os como dois dos principais elementos da narrativa e também foco de vários discursos metodológicos que se preocuparam com a tradição literária. Especialmente pelo fato de tais elementos estarem articulados de forma tão interessante e particular em Terra em transe. Personagem e tempo são, no texto de Glauber, coodependentes e coodeterminados.

Ao compreender a narrativa como a humanização do tempo, podemos perceber a importância da instância temporal na criação diegética ficcional. Entender a articulação do tempo da narrativa é entender o seu posicionamento dentro de uma já consagrada tradição. O tempo é, para Todorov, e para Genette que recupera essa sua categoria, um dos principais problemas da narrativa:

Adoto sem qualquer emenda a primeira categoria na definição que acabo de citar, e que Todorov ilustrava com notas sobre as <<deformações temporais〉>, isto é, as infidelidades à ordem cronológica dos acontecimentos, e sobre as relações de encadeamento, de alternância ou de <<encaixe〉> entre as diversas linhas de acção constitutivas da história; mas acrescentar-lhe umas considerações sobre o <<tempo da enunciação〉> e o da <<percepção〉> narrativa. (GENETTE, 1979, p. 27) 
As considerações de Genette diferem da definição sobre temporalidade em Todorov, pois enquanto esse estava preocupado com as relações entre o tempo da escrita e o tempo de leitura, o Francês buscava compreender as relações de tempo entre a narrativa e a narração. Desta forma, este trabalho se articulará de modo a aproximar-se de certas categorizações temporais propostas por Genette. Em especial a noção de ordem.

O estudo da ordem temporal da narrativa se preocupa em comparar, quando possível, a ordem dos eventos na estória e a ordem que tais eventos se localizam na estrutura narrativa. À discordância entre essas duas ordens dá-se o nome de anacronia, esta que é, segundo Genette, um dos recursos mais tradicionais da narração literária. Atrevo-me a alargar afirmação de Genette: a anacronia, em suas diversas formas, herdada da tradição literária, tornou-se um dos recursos mais tradicionais da narrativa artística, como bem pode ser conferido no cinema. Desta forma, Terra em transe, como escrito literário da modernidade, não escapou a esse recurso tão característico do fazer literatura.

A experiência temporal em sua totalidade na obra discutida dá-se de um modo bastante particular; por pertencer ao gênero roteiro, sua estrutura é constituída por uma série de sequências, essas, por sua vez, formadas por uma série de cenas. Quando tratamos de um romance não é incomum que também nos refiramos a essa noção de cena, estudamos essa unidade da narrativa romanesca e a compreendemos como parte importante da narrativa, mas há no romance a existência de uma estrutura/unidade não cênica, tão importante quanto. Algo que existe entre cenas e sequências, conectando-as (ainda que de forma desconexa), são transições, diálogos internos de personagens e/ou narrador, interpolações de caráter ensaístico etc. outra funcionalidade dessas unidades inter-cênicas e inter-sequenciais é, justamente, a da expressão da passagem do tempo. No roteiro, porém, assim como no drama, não há essa unidade inter-cênica que emule a passagem do tempo, ao contrário, tal anúncio acontece de forma intracênica. O final de cada cena há - teoricamente - de servir como a coda de sua própria cena/sequência e o anúncio da que virá. (Digo teoricamente, pois convencionalmente um dos principais mandamentos dos manuais de roteiro fala exatamente da necessidade de uma boa costura inter-cênica e inter-sequencial). Observemos agora alguns pares de cenas de Terra em transe. 


\section{Sequência $3^{2}$}

$(\ldots)^{3}$

O Chefe se aproxima com uma garrafa de cerveja e dois copos.

Oferece a Paulo. Paulo bebe dois goles, acende o cigarro e sai. O chefe fica olhando com experientes olhos de gráfico. As maquinas giram, ruído abafante. Vários planos de imagens rápidas, políticas, ruídos de impressora. Continuam o letreiro

\section{Sequência 4}

Uma casa moderna, entre árvores, colocada para o alto. $\mathrm{O}$ carro de Paulo. Paulo sobre as escadas da casa, está de terno escuro.

Interior. Casa de Silvino sentado, camisa aberta. Aparece ao fundo, por uma porta de vidro, Paulo: fotos da conquista espacial, fotos de Silvino.

Silvino lê jornais. Silvino nota a presença depois de ouvir um leve ruído. Reergue-se do seu sono. A imagem de Paulo que se aproxima. Silvino compõe-se, sente Paulo, levanta-se e o abraça com grande emoção. Música clássica.

Passou algum tempo. CAM afasta-se das rosas, no jardim de Silvino. Manhã insólita.

(ROCHA, 1985, p. 118)

A primeira sequência traz a cena de apresentação do personagem principal, Paulo. Tal apresentação dá-se em forma de ação, Paulo se demite do jornal após uma conversa com seu patrão na qual the diz que não deseja mais seguir trabalhando para um veículo de comunicação com interesses corporativistas. A segunda sequência segue a introdução de Paulo, agora tensionada com mais um personagem. Pode-se reconhecer nas duas sequências pontos de tensão: na primeira, o olhar atento do chefe, dois goles apenas da bebida oferecida, o cigarro aceso, o ruído abafante, as imagens políticas; na segunda, o terno escuro, o abraço com grande emoção, a música clássica. A atmosfera grave das duas poderia sugerir que

2 Sequências numeradas como no original.

3 A sequência inicia-se antes do trecho aqui redigido. Paulo se demite do jornal. 
: sejam, de fato, temporalmente próximas, que a ordem em que aparecem : na narrativa coincida com a ordem da estória, que a primeira é causa da segunda: Paulo após perder o emprego procura seu amigo Silvino. Todas essas suposições certamente são válidas e possíveis, mas não há nada entre as sequências que nos garanta sua relação temporal. É preciso buscar dentro das sequências, nos detalhes e estar preparado para não achar imediatamente o que se procura. Especialmente no caso dos textos de Glauber, a busca precisa ser mais delicada, atenta. É convencional, pelos moldes do roteiro hollywoodiano que cada cena se inicia com uma indicação de locação e horário, desta forma teríamos na sequência 4 algumas diferentes cenas. Fazendo o exercício de conformidade, teríamos algo assim:

\section{CENA Naㅡ. INTERNA. RUA DA CASA DE SILVINO - DIA ou NOITE}

As informações desse tipo de cabeçalho prescrito não é, de maneira alguma, apenas um elemento inter-cênico, faz parte da cena, a caracteriza e fornece informação sobre ela. É, porém, um elemento heterodiegético, ao passo que rompe o pacto ficcional, ainda que tão brevemente, ao anunciar que o que estar por vir é uma cena enumerada num conjunto de outras cenas. Glauber abdica desse modo de organização, permite que suas cenas se toquem dentro de uma sequência, num malabarismo quase indiscernível entre o que é heterodiegético e o que é homodiegético.

A Paulo é permitida a fluidez de passar de um lugar a outro, sua presença metonímica na figura do carro passando ao topo da escada, ao interior da casa, depois ao jardim. O tempo é justamente o tempo do movimento, do entre ações. É o tempo que se anuncia "Passou algum tempo". Ainda mais interessante é perceber os elementos linguísticos usados para emular as ferramentas cinematográficas. A forma CAM, diminutivo de câmera, nos direciona o olhar, lembra-nos de nossa condição voyeurística. A música toca em nossos ouvidos e nos perguntamos se eles também podem ouvi-la. Estamos no tempo da estória sem de fato fazer parte dela, estamos presenciando como se escondidos por um véu de invisibilidade. Contudo, de jeito algum o que vemos é o como é, antes vemos o que o narrador nos urde a prestar mais atenção. No drama saberíamos que estavam Silvino e Paulo no jardim e a isso nos ateríamos, no roteiro, porém somos seduzidos a ignorar a imagem de Paulo e Silvino, mesmo que por 
um segundo apenas, e olhar as rosas e o mar. Através dessa possibilidade de eleição de imagens, o tempo do roteiro é percebido de maneira sensual, : i.e através dos sentidos: a música que se inicia forte e vai esvaindo-se, o cheiro das rosas já perdido, o movimento em direção ao mar, a visão da manhã insólita; a gravata frouxa numa sequência anterior, depois o carro fechado e logo em seguida o terno escuro no topo da escada.

Num par de sequências da página 125, temos duas cenas cuja continuação temporal dentro da narrativa é articulada pela alusão musical que atravessa as duas sequências:

\section{Sequência 5}

\section{(...)}

\section{SILVINO}

Embaixador, para se subir no Governo Federal é preciso ser de esquerda. Comunista não, veja bem...De esquerda.

CAM sobe com música. TRAV aéreo. Os vaqueiros cercam a boiada que se movimenta. $\mathrm{O}$ americano, no jipe, descreve um circulo, buzinando e gritando como um cowboy.

CAM afasta-se, estoura música carnavalesca. CORTE

\section{Sequência 6}

TRAV DESCONTÍNUO. Mulheres fantaseadas dançando histéricas. Estamos num baile de Carnaval, num Clube pequeno.

Animação.

A indicação da música carnavalesca quando se inicia ao fim da sequência número cinco, por não fazer parte da diegese da cena, funciona como o prelúdio da sequência seguinte, i.e, um indício de um acontecimento que ocorrerá (ou ocorreu) em outra situação temporal. O corte que abruptamente encerrou o tempo de leitor (já que a ação em andamento continuará a ser executada ainda que distante de nossos olhos vouyerísticos) é amansado pela música que continua a tocar. Ela faz parte do universo diegético da narrativa na sequência número seis, pois os personagens dançam conscientes de acordo com seu ritmo e, ao mesmo 
tempo, ela nos zomba em seu caráter técnico. Pois funciona como uma : indicação sonora que perpassa o cabeçalho de transição seqüencial que, denuncia a autoconsciência ficcional do texto.

As artimanhas em relação ao tempo da narrativa ocorrem dentro do roteiro de Glauber nas mais diversas formas, podendo acontecer tanto nas estruturas cênicas e nos apontamentos técnicos, quanto nas ações e no discurso dos personagens. Observemos o seguinte trecho: “[...] Como você Paulo, que me abandonou para trabalhar com Moura, que não se casou com Marina, que agora perdeu o emprego e volta para mim como o filho pródigo, com a humilde certeza de que apenas lhe amo.”

Apesar de configurar uma sentença relativamente curta, o recorte do discurso de Silvino toca o tempo da narrativa por vezes inserindose neste e por vezes extrapolando-o. Em relação ao ponto de partida da narrativa, quando nos é apresentado o personagem principal, temos quatro acontecimentos narrados por Silvino: Paulo deixa Silvino para trabalhar com Moura, Paulo não se casa com Marina, Paulo perde o emprego e Paulo volta para Silvino. Apesar de não poder afirmar com certeza que tas eventos são relatados de acordo com sua ordem cronológica dentro da estória, baseados nos dois últimos acontecimentos (a perda do emprego e a volta) suponhamos que tal ordem tenha sido preservada. Desta forma, os dois últimos acontecimentos estão inseridos dentro do tempo da narrativa, Paulo deixando o emprego na sequência número 3 e a volta de Paulo que está ocorrendo no tempo do discurso. Os dois primeiros, contudo, são de um tempo anterior ao início da estória. Temos, então, uma analepese mista, pois alcança um tempo anterior ao do início da narrativa, mas se estende até um ponto posterior.

Cada parte da analepese apresentada pela fala de Silvino serve a um propósito diferente dentro da estória. A primeira lança uma luz explicativa sobre a atmosfera tensa da interação entre Paulo e Silvino. A segunda nos fornece informação complementar para a caracterização do personagem, um vislumbre em seu passado sentimental/amoroso e ao mesmo tempo a apresentação primeira de um personagem que aparecerá mais tarde na narrativa. A terceira é uma revisitação de um acontecimento já contemplado anteriormente. A quarta apresenta a impressão de Silvino sobre a volta de Paulo e, consequentemente, a impressão de Silvino sobre sua relação com Paulo. 
A ação negativa do terceiro acontecimento (Paulo não se casou com Marina) é, inclusive, retomada e alargada em informação quando a : personagem Marina é propriamente introduzida na narrativa:

Numa mesa de bar estão Álvaro, Marina e Paulo. Conversam, informais, tontos e sonolentos. Esta cena tem um tom de sonho. A marcha-rancho ao fundo é substituída por outra. PAULO

\section{E assim Álvaro se casou com Marina}

O somatório informativo dos acontecimentos 'Paulo não se casou com Marina' mais 'Álvaro se casou com Marina', embora anteriores ao tempo inicial da narrativa, é crucial para o melhor entendimento dos personagens e das relações estabelecidas entre eles. Apesar do narrador não dizer (ou talvez não conhecer) o início do presente diálogo, i.e, as falas que antecederam imediatamente a enunciação de Paulo que vemos acima, o acontecimento do casamento entre Álvaro e Marina complementa informação de uma fala ocorrida quatro sequências atrás. Aliás, quão interessante é para uma discussão sobre o narrador do roteiro é a observação 'Conversam, informais, tontos e sonolentos'. Somos informados de que conversam, de como parecem ao conversar, mas a conversa em si só nos chega depois, com um atraso. Não sabemos se o diálogo começou há muito tempo ou não, como também não sabemos se o narrador escolheu nos impor tal ignorância. Talvez, apenas talvez, nossa ignorância seja compartilhada em igual medida e a iluminação só seja possível com o transcorrer do tempo que leva para que a audição alcance o que a visão já de longe apreende. Eles conversam, tontos, e não podem parar para que os observadores - o narrador, o leitor -aproximem-se o suficiente. O tempo da aproximação é o tempo do diálogo perdido, totalmente irrecuperável em tal momento. Caminhássemos mais rápido, quem sabe ouviríamos a fala anterior que motivara o "E assim" ou mesmo o silêncio duro que pode preceder a enunciação de um coração partido sentado numa mesa de bar - já tonto e sonolento - frente ao amor perdido e aquele que achou tal amor.

No seu livro A teoria do drama moderno, Peter Szondi (2001) dirá 
: que no drama não existe outro tempo que não o presente ou, ao menos,

: que não pode haver outro tempo em cena que não o presente; que ao ocorrer vira passado, mas num lugar extra-cênico qualquer. Isto é dizer que ainda que as cenas sejam descontinuadas, que a ordem da narrativa difira muito da ordem da estória, cada cena existe em forma de presente. Sua configuração dialógica assegura esse presente absoluto que, nas palavras de Szondi, está prenhe de um futuro que só aparecerá em sua forma presente numa cena por vir.

Pensando na clássica distinção platônica entre mímesis (imitação) e diegese (narrativa), o roteiro encontra-se, assim como o romance, dentro do espectro das formas mistas. No romance o passado é comumente assumido, está declarado pelo narrador que se refere a ele e o revela - como o vê - para o leitor. No roteiro, contudo, há primeiramente a sensação do tempo primário como no drama, aquele tempo que não é relatado, mas que está acontecendo em ações e falas “originárias” (SZONDI, 2001). Entretanto, a sensação é apenas isso: uma sensação. Há pouco de primário no roteiro, pois o primário está nas cenas mais dialógicas- as quais a tradição roteirística recomenda evitar.

\section{Sequência 8}

(...)

O telescópio gira outra vez: agora é Paulo que olha. Ouvem-se ruídos de despedidas. Marina aproxima-se, num movimento de CAM.

PAULO

Para mim tanto faz.

MARINA

É uma experiência séria.

PAULO

Desde quando você se interessa por coisas sérias?

MARINA

Paulo...

PAULO

Vocês não mudaram nada. Ou melhor, mudaram, estão mais sofisticados, mais cultos, mais... 
E você mais consciente.

Paulo, então, com violência, agarra o rosto de Marina com as duas mãos, com grande violência, como se fosse beijá-la. Marina assusta-se, mas depois fica a esperar o beijo. Nos olhos de Paulo acende-se a antiga paixão. Ouvem-se os acordes iniciais do Samba Prelúdio na guitarra de Badem Powell. Paulo larga Marina e anda pela varanda. Marina compõe, tensa, sensual.

O presente absoluto de que nos fala Szondi parece estar articulado na forma dialógica no início do texto. Paulo e Marina conversam "primariamente", não houve nenhuma introdução direta a sua fala, i.e um marcador de discurso reportado, que não o surgimento de seus nomes. Contudo, a continuação da descrição cênica 'Marina aproxima-se' prepara para o diálogo. A previsão (o aproximar-se) e sua realização (o diálogo) coexistem na mesma cena. É como se houvesse uma pausa maior entre o fim da linha de ação e o início do diálogo, pausa suficiente para que o leitor alcance o narrador e os dois possam testemunhar a estrutura dialógica em sua forma primária. O narrador está esse um segundo a frente. Como um locutor de jogo de futebol cuja excelência será medida quão menor for o seu atraso em narrar a jogada, o narrador do roteiro nos conta a última ação enquanto a próxima está em andamento e assim sucessivamente.

Desta forma, apesar dos verbos no presente, o narrador, através de estruturas coesivas - 'Paulo, então,', 'Marina assusta-se, mas depois fica a esperar o beijo' - e de indicações de informação adquirida do passado - 'Nos olhos de Paulo acende-se a antiga paixão' entrega a sua posição de mediador temporal, o seu posicionamento propriamente narrativo. Enquanto no drama o tempo é o presente absoluto e no romance ele pode alcançar o pretérito mais longínquo e desejar o futuro mais improvável, no roteiro o tempo é o do passado imediato. Aquele passado configurado pelo breve atraso existente entre o que o narrador presencia e aquilo que ele reporta. 
Sequência 19

(...)

- Billy, Paulo, Álvaro e Marina. Tudo agora é movimento, Billy comanda as ações na sua agitação, Billy abraça Paulo.

BILLY

Londres estava linda. Mas a Marina,sabe, Paulo, eu amor a Marina, o Álvaro compreende, aceita, mas eu sofro com isto.

Marina se movimenta pegando no rosto de Paulo.

\section{MARINA}

Olha a cara do Paulo meu amor... Descobriu o Nordeste, está mais politizado.

Mais uma vez temos a linha de ação anunciando a chegada do diálogo, o abraço de Billy em Paulo é, ao mesmo tempo, o passado imediato sendo reportado e a indicação para a próxima ação, no caso a fala de Billy. E da mesma forma funciona o movimento de Marina ao pegar o rosto de Paulo. É interessante, porém, observar que o passado imediato do roteiro não é absoluto, i.e não é o passado cuja distância em relação ao presente configura uma constante. Como observado no romance por Genette, o tempo na narrativa do roteiro tem um alcance mutável - ainda que bem menor que o do romance. Isto pode ser claramente constatado pela sentença 'Tudo agora é movimento, Billy comanda as ações na sua agitação'. O narrador toma a decisão de simplificar um dado conjunto de ações na forma reduzida 'tudo é movimento', como se numa ânsia de tocar o presente prefere não narrar as ações singulares, parte para o relato do que julga mais importante, i.e que Billy, em sua agitação, comanda as ações. Há, então, o tempo economizado das ações sendo simplificadas pela ideia de movimento e, simultaneamente, o tempo gasto para que tal decisão fosse tomada: o tempo do julgamento, o tempo do processo subjetivo de percepção das ações.

$\mathrm{Na}$ passagem das sequências numeradas por Glauber, temos evidentemente a mudança de momento temporal, apesar de ser difícil precisar sobre a ordem dos acontecimentos dentro da estória, uma vez que não há indicações diretas sobre a distância temporal entre as sequências, 
o quebra-cabeça nos parece montado em pequenos indícios remissivos. Primeiro temos Paulo abandonando o emprego, logo depois Silvino : comenta o fato. Vemos Paulo, Billy e todos os outros no cenário árido nordestino e depois Marina falando a Álvaro sobre o amadurecimento de Paulo após ter conhecido o Nordeste. Desta forma parece seguro assumir que em Terra em Transe a ordem dispositiva das sequências coincide com a ordem da estória. Contudo, como já foi tratado, internamente, no discurso direto dos personagens, a temporalidade é explorada e subvertida, escapando de uma fixidez? anacrônica perene. As distorções temporais envolvendo o tempo da narrativa e o tempo da estória, tão comuns nas narrativas, como pontua Metz (1974) e relembra Genette (1979), é ainda mais distorcida no roteiro. Ainda internamente, outros elementos denunciam uma virada para um tempo pertencente a outra diegesis. Observemos o trecho a seguir:

\section{Sequência 4}

(...)

\section{SILVINO}

(...) Como as rosas, as formas perfeitas, abstrações, as cores. As rosas estão do espírito, no absurdo, na eternidade; os comunistas não compreendiam isto, a minha fome de absoluto! Eu cheguei a Deus na maturidade, quando vi minhas esperanças perdidas, minha juventude. Quando somos jovens queremos mudar o mundo; todos somos comunistas aos vinte anos; aos vinte anos somos poetas e revolucionários e a única coisa que conseguimos...

TRAV- Alguns slides na parede. Uma imagem de bela mulher, foto antiga.

SILVINO

... é estragar o amor com a inexperiência. Olho hoje esta fotografia. Onde andará Helena?

Mais uma vez chegamos à sequência de número quatro - não há de se estranhar que, num estudo sobre as discrepâncias e distúrbios da temporalidade na narrativa, eu me permita essa analepese. Enquanto Silvino em seu discurso revisita um tempo outro - o da juventude - as 
: reticências nos apresentam a imagem de uma foto antiga figurando uma : bela mulher. Essa imagem é a marca de outro momento, outro tempo, e concomitantemente prevê a fala de Silvino que virá, através da qual conhecemos o nome da mulher, Helena. Ora, a linearidade ontológica da leitura textual nos obriga a uma sequencialidade que, na verdade, deseja ser simultânea. Num filme, provavelmente, não haveria a pausa longa entre o 'conseguimos...' e o '... é estragar o amor com a inexperiência', eles se seguiriam no ritmo mais comum da fala humana enquanto os slides na parede e a imagem de Helena fosse surgindo. O tempo da leitura, porém, não permite esse enquanto. Há primeiro uma coisa e depois a outra. Assim, existe o tempo da disposição linear do texto e o tempo do desejo pela simultaneidade.

Enquanto o roteiro, como qualquer outro texto, não tem outra temporalidade senão aquela que toma metonimicamente de empréstimo à sua própria leitura (GENETTE, 1979 p.33), em seu jogo cabe ao menos mais uma preocupação temporal que o romance, por exemplo, ignora. Observemos mais uma vez o trecho selecionado, quantos segundos são necessários para que atravessemo-no? Quantos segundos podem ter durado a fala de Silvino? Certamente que dois leitores diferentes, independente da duração da fala de Silvino - se é que podemos mesmo falar de tal duração, desse pseudo-tempo -, podem ler a mesma quantidade de palavras em tempos completamente diferentes. Ainda assim, essa mesma quantidade de palavras se traduzida filmicamente terá uma temporalidade absoluta a ser compartilhada pelos espectadores.

Esse tipo de construção dialógica, do discurso auto-contemplativo, monológico e estendido é deveras repreensível aos olhos dos autores de manuais:

O melhor conselho sobre escrever diálogo para filmes é não escreva. Nunca escreva uma linha de diálogo quando você pode criar uma expressão visual. A primeira coisa a se pensar quando se escreve uma cena deve ser: como eu posso escrever isso em uma maneira puramente visual, sem ter de lançar mão de uma única fala? Obedeça a Lei dos Retornos diminutivos: quanto mais diálogo você escreve, menos efeito o diálogo tem. (MCKEE, 2006, p. 367) 
Dentre várias questões que certamente influenciaram para que existisse tal ojeriza em relação a um uso mais forte de diálogos no roteiro - entre elas o desejo de se afastar do drama e o caráter naturalista da linguagem cinematográfica - está a convenção de que uma página de roteiro equivale a um minuto de projeção. Apesar de não ser possível comparar a duração da sequência em relação ao filme, dado que a versão fílmica de Terra em transe difere bastante em seu enredo, podemos pensar na configuração intelectual que é empregada no exercício de escrever algo - uma sequência de acontecimentos, um diálogo, uma série de imagens contemplativas etc. - pretendido para ocupar um dado tempo no ecrã.

Muito embora este trabalho tenha como preocupação o texto, não se pode ignorar que o texto tem como preocupação o filme. Desta forma, o tempo no roteiro além de configurar a dualidade característica das narrativas textuais ainda preocupa-se com a transposição da ideia temporal para o cinema. É interessante observar a articulação de noções de temporalidades diversas. $\mathrm{O}$ mover das cenas, e das sequências no caso específico de Terra em transe, sem dúvida expressa a passagem do tempo de maneira particular. A previsão do exercício de montagem, por exemplo, permite que seja feita uma viagem vertiginosa por diversas paisagens cujo tempo real não permitiria:

\section{Sequência 14}

- Nordeste: Paisagem seca, CORTE, novo TRAV - uma capital qualquer, novo TRAV sobre uma aldeia miserável de camponeses, um caminhão pequeno, massa, sobre o caminhão numa espécie de palanque improvisado, Silveira fala.

CENAS: o trabalho primitivo nas rodas de fumo, nas moendas, nos portos - sempre um trabalho escravo.

A palavra CORTE, apesar de ser no texto de Glauber uma indicação de direção - dado que ele seria o próprio diretor - existe nos outros roteiros como o recurso da narrativa textual. Tanto que seu uso não é desencorajado pelos autores de manuais como são, por exemplo, o uso de termos que indicam cortes específicos: Apague CORTA PARA, CORTE 
SECO PARA, FUSÃO PARA e outras transições; o leitor supõe que todas as mudanças de ângulo são feitas com um corte. (MCKEE, 2006. p, 370). O corte muda o ângulo e, simultaneamente, corta o tempo. Acabado está o tempo da paisagem seca e é chegado o tempo da capital, mas a mudança feita com o corte, tão incisivo, não é de todo pacífica, ao contrário, é dura e notável. A interrupção do tempo de uma coisa para outra fala da relação entre as duas, de sua tensão e de seu contraste.

O tempo no roteiro vai se revolvendo, se misturando, se escondendo e se confundindo. Uma passagem frenética entre paisagens leva o tempo de umas poucas palavras no texto, levará apenas alguns poucos segundos no tempo do produto fílmico ao passo que pretenderá representar o correr de horas, talvez dias, meses ou mesmo anos, na diegese da ficção.

O tempo é, simultaneamente, essência e mistério no texto.

\section{REFERÊNCIAS BIBLIOGRÁFICAS}

BARTHES, Roland. O efeito do real. In: BARTHES, Roland et al. Literatura e semiologia. Petrópolis: Vozes, 1972

FIELD, Syd. Manual do roteiro: os fundamentos do texto cinematográfico. Rio de Janeiro: Objetiva, 2001.

GENETTE, Gerárd. O discurso da Narrativa. Lisboa: Arcádia, 1979

MCKEE, Robert. Story: Substância, estrutura, estilo e os princípios da escrita de roteiros. Curitiba: Arte\&Letra, 2010.

METZ, Christian. Film Language: A semiotics of the Cinema. Chicago: University of Chicago press, 1974

ROCHA, Glauber In: SENNA, O. (org). Roteiros do Terceyro Mundo. Rio de Janeiro: Alhambra/Embrafilme, 1985.

SZONDI, Peter. Teoria do drama moderno (1880-1950). Tradução: Luiz Sérgio Repa. São Paulo: Cosac \& Naif Edições, 2001.

TODOROV, Tzvetan. As estruturas narrativas. São Paulo: Perspectiva, 2006. 